Jurnal Riset Agama

Volume 1, Nomor 1 (April 2021): 45-58

https://journal.uinsgd.ac.id/index.php/jra

\title{
Berbakti Kepada Orang Tua dalam Ungkapan Hadis
}

\author{
Hofifah Astuti \\ Jurusan Ilmu Hadis, Fakultas Ushuluddin \\ UIN Sunan Gunung Djati Bandung \\ hofifah.astuti24@gmail.com
}

\begin{abstract}
The purpose of this study is to discuss the command to be filial to parents in the hadith. This research method uses a qualitative type through literature study by applying content analysis. The discussion of this research includes the meaning of birrul walidain (filial piety to parents), the hadith orders birrul walidain (filial piety to parents), the forms of birrul walidain, and the virtues of birrul walidain (filial piety to parents). This study concludes that birrul walidain or filial piety to both parents has a special position in Islamic teachings. The matter of filial piety to parents has been regulated both in the Qur'an and Hadith. Devotion to parents according to the hadith is an obligation equivalent to faith and jihad and taqwa which applies not only when parents are still alive but also when they have died. This research is expected to have benefits for enriching the treasures of Islamic knowledge.
\end{abstract}

Keyword: Birrul walidain, Hadith, Parents, Syarah

\begin{abstract}
Abstrak
Tujuan penelitian ini adalah membahas perintah berbakti kepada orang tua dalam hadis. Metode penelitian ini menggunakan jenis kualitatif melalui studi pustaka dengan menerapkan analisis isi. Pembahasan penelitian ini meliputi makna birrul walidain (berbakti kepada orang tua), hadis perintah birrul walidain (berbakti kepadaorang tua), bentuk-bentuk birrul walidain, dan keutamaan birrul walidain (bebakti kepada orang tua). Penelitian ini menyimpulkan bahwa birrul walidain atau berbakti kepada kedua orang tua mempunyai kedudukan yang istimewa dalam ajaran Islam. Perkara berbakti kepada orang tua telah diatur baik dalam Al-Quran maupun Hadis. Berbakti kepada orang tua menurut hadis merupakan kewajiban setara dengan iman dan jihad serta taqwa yang bukan saja berlaku ketika orang tua masih
\end{abstract}


Jurnal Riset Agama, Volume 1, Nomor 1 (April 2021): 45-58

Hofifah Astuti / Berbakti Kepada Orang Tua dalam Ungkapan Hadis

hidup melainkan pula di saat mereka telah meninggal dunia. Penelitian ini diharapkan memiliki manfaat bagi pengayaan khazanah pengetahuan Islam.

Kata kunci: Birrul walidain, Hadis, Orangtua, Syarah.

\section{Pendahuluan}

Kedua orang tua adalah hamba Allah yang menjadi perantara hadirnya manusia di dunia. Lebih dari itu, mereka juga orang yang penuh akan kasih sayang, merawat, membesarkan, mendidik dan mencukupi kebutuhan, baik secara lahir maupun batin. Sudah sepantasnya kita selalu berbakti kepada orang tua, karena orang tua sudah rela berkorban demi membahagiakkan dan muwujudkan keingginan anak-anaknya (Alihasan, 2018). Dalam ajaran Islam berbuat baik orang tua atau birrul walidain mempunyai kedudukan yang istimewa, dan setiap anak mempunyai kewajiban terhadap orang tuanya agar mereka senantiasa berbuat baik kepada keduanya, namun masih terdapat anak-anak yang tidak memperlakukan orang tuanya sebagaimana mestinya. Banyak sekali anak yang tidak lagi memperdulikan bagaimana bentuk-bentuk ketika berbicara, bergaul, mencintai serta mendoakan kedua orang tuanya. Sering kali anak berlaku seenaknya terhadap kedua orang tuanya. Padahal Perintah berbakti kepada orang tua telah Allah atur baik dalam Al-Qur'an maupun Hadis (Elisa, Yuyun, 2018).

Sejumlah pakar telah melakukan penelitian mengenai bahasan ini, diantaranya dalam artikel berjudul Elisa, Yuyun (2018), "Birrul Walidain dalam Perspektif Islam," Fakultas Tarbiyah dan Keguruan UIN Ar-Raniry Darussalam Banda Aceh. Artikel ini menggunakan penelitian kepustakaan (library research) dengan pendekatan kualitatif. Hasil dan pembahasan artikel ini adalah dapat menambah sumber bacaan tentang birrul walidain dan dapat menumbuhkan kesadaran bagi seseorang yang berstatus sebagai anak bagaimana seharusnya memperlakukan kedua orang tuanya. Artikel ini menyimpulkan bahwa seorang anak harus selalu lemah lembut tatkala berbicara dengan kedua orang tua, harus sangat berhati-hati menjaga setiap tutur kata yang keluar dari mulutnya, seorang anak wajib memperlakukan orang tua dengan baik, tidak ada batasan waktu untuk berbakti kepada kedua orang tua, dan seorang anak harus mengutamakan orang tuanya dibandingkan orang lain (Elisa, Yuyun, 2018). Hakim, Lukmanul (2019), judul "Studi Hadits Birrul Walidain (Hadis Sunan Ibn Majah No Indeks 3664 Perspektif Muhammad Nashiruddin Al-Albani)." Penerbit UIN Sunan Ampel Surabaya. Penelitian ini menggunakan metode kepustakaan (library research). Hasil dan pembahasan penelitian ini adalah penilaian Muhammad Nashiruddin Al-Albani hadis tentang berbakti kepada kedua 
Jurnal Riset Agama, Volume 1, Nomor 1 (April 2021): 45-58

Hofifah Astuti / Berbakti Kepada Orang Tua dalam Ungkapan Hadis

orang tua setelah meninggal dunia dalam sunan Ibn Majah bernilai dhaif. Artikel ini menyimpulkan mengenai pemaknaan hadis ini dan perbuatan baik yang harus diamalkan seorang anak setelah orang tua meninggal (Hakim, Lukmanul, 2019). (Zulhamdi, 2015), judul “Konsep Birrul Walidain dalam Perspektif Hadis dan Relevansinya dengan Pembinaan Akhlak." Undergraduate thesis, IAIN Padangsidimpuan. Penelitian ini menggunakan metode studi pustaka dengan pendekatan tafsir maudu'i. Asumsi hasil dan pembahasan penelitian ini adalah berkaitan dengan bidang ilmu hadis, tepatnya tentang birrul walidain dalam perspektif hadis. Penelitian ini menyimpulkan bahwa mengetahui dan mengamalkan birrul walidain dalam kehidupan merupakan perintah mutlak (Zulhamdi, 2015).

Berbagai penelitian terdahulu berharga dalam penyusunan kerangka berpikir penelitian ini. Birrul walidain adalah berbuat baik, menunjukkan kasih sayang, kelemah-lembutan dan memperhatikan keadaan orang tua serta tidak melakukan perbuatan buruk terhadap orang tua (Jamil, 2007). Berbakti kepada orang tua merupakan amal baik yang memiliki tingkatan yang sangat tinggi (Elisa, Yuyun, 2018). Allah SWT mengurutkan perintah berbuat baik pada kedua orang tua dengan perintah bertauhid, "Berlaku hormat dan khidmat, cinta dan kasih" (Elisa, Yuyun, 2018). Dalam hadis terdapat perintah dan beragam cara untuk berbakti kepada kedua orang tua (Hakim, Lukmanul, 2019). Di dalam sebuah riwayat dipaparkan seorang anak harus berbakti kepada kedua orang tua setelah meninggal dunia (Zulhamdi, 2015). Sebanyak apapun seorang anak berusaha untuk membalas jasa orang tuanya tidak akan mampu seorang anak membalasnya bahkan mengimbangi kebaikan orang tua saja tidak bisa (Elisa, Yuyun, 2018). Mendoakan orang tua adalah salah satu anjuran agama, baik pada masa hidup mereka maupun setelah wafatnya (Alihasan, 2018). Anak harus berbakti kepada orang tuanya, itu adalah hukumnya wajib, dan bila tidak berarti ia berdosa karena melanggar kewajiban tersebut (Alihasan, 2018).

Berdasarkan paparan diatas, penulis berusaha menyusun formula penelitian, yaitu rumusan masalah, pertanyaan penelitian, dan tujuan penelitian (Darmalaksana, 2020). Rumusan masalah penelitian ini adalah terdapat terdapat konsep berbakti kepada kedua orang tua dalam ungkapan hadis. Pertanyaan utama penelitian ini adalah bagaimana konsep berbakti kepada kedua orang tua dalam ungkapan hadis. Sedangkan pertanyaan secara terperinci yaitu, bagaimana pandangan umum tentang berbakti kepada orangtua, bagaimana hadits tentang birrul walidain (berbakti kepada orangtua), bagaimana keutamaan dan bentukbentuk birrul walidain. Tujuan penelitian ini yakni untuk menjelaskan konsep berbakti kepada kedua orang tua dalam ungkapan hadis.

\section{Metode Penelitian}


Jurnal Riset Agama, Volume 1, Nomor 1 (April 2021): 45-58

Hofifah Astuti / Berbakti Kepada Orang Tua dalam Ungkapan Hadis

Metode penelitian ini merupakan jenis kualitatif melalui studi pustaka dengan analisis isi (Darmalaksana, 2020).

\section{Hasil dan Pembahasan Penelitian}

Hasil dan pembahasan di bawah ini.

\section{Pandangan Umum tentang Birrul Walidain}

Birrul berasal dari kata lisan al-'Arabi kata birrul walidain berasal dari gabungan dua kata, yakni kata al-birrul dan kata al-walidain, yang mana kata birru yang berarti berbuat baik, kebaikan, berbakti. Mnurut Kamus Besar Bahasa Indonesia kebaikan atau baik artinya adalah sifat manusia yang dianggap baik menurut sistem norma dan pandangan umum yang berlaku atau yang mendatangkan keselamatan, keberuntungan sesama manusia (Bahasa, 1989). Sedangkan al-walidain yang merupakan bentuk tastniah dari kata al-walidu yang berarti kedua orang tua yaitu ayah dan ibu (Munawir, 1987). Dengan demikian istilah birrul walidain dapat diartikan sebagai berbuat baiknya seorang anak kepada kedua orang tuanya yang telah melahirkan, merawat dan menjaganya. Birrul walidain juga sering dimaksudkan sebagai berbuat baik/berbakti kepada kedua orang tua (Shaari, 2017).

Menurut Fathurrahman, birrul walidain adalah berbuat baik, menunjukkan kasih sayang, kelemah-lembutan dan memperhatikan keadaan orang tua serta tidak melakukan perbuatan buruk terhadapnya (Fathurrahman, 2007). Al-Jauzi berpendapat bahwa birrul walidain adalah berbuat baik dan berlapang dalam kebaikan (ihsan) kepada orang tua, dalam hal perkataan, perbuatan dan niat.

Dalam buku "Birrul Wālidain" Yazid bin Abdul Qadir Jawas, beliau mengemukakan bahwasanya berbakti kepada kedua orang tua yaitu menyampaikan kebaikan kepada kedua orang tua semampu kita dan bila memungkinkan mencegah gangguan terhadap keduanya (Hakim, Lukmanul, 2019). Adapun menurut Abdullah Nashih Ulwan, secara istilah birrul walidain artinya adalah berbakti, taat, berbuat ihsan, memelihara keduanya, memelihara dimasa tua, tidak boleh bersuara keras apalagi sampai menghardik mereka, mendo'akan keduanya lebih-lebih setelah mereka wafat, dan sebagainya termasuk sopan, santun yang semestinya terhadap kedua orang tua (Musfiroh, 2019).

Sedangkan menurut Ahmad Izzuddin Al-Bayunni berbakti adalah berbuat baik kepada keduanya, melaksanakan hak-hak keduanya, selalu mentaati keduanya dalam hal yang bukan merupakan pendurhakaan kepada Allah SWT, menjauhi segala yang mengecewakan keduanya dan melakukan perbuatan yang diridhainya. Dengan demikian dapat kita pahami bahwa berbakti itu adalah suatu perbuatan yang menjurus kepada hal-hal yang baik dan tidak untuk dilakukan dengan pelanggaran, 
Jurnal Riset Agama, Volume 1, Nomor 1 (April 2021): 45-58

Hofifah Astuti / Berbakti Kepada Orang Tua dalam Ungkapan Hadis

sehingga menimbulkan ketentraman pada diri serta hati seseorang (Utami, 2017).

Anak harus berbakti kepada orang tuanya, itu adalah hukumnya wajib, dan bila tidak berarti ia berdosa karena melanggar kewajiban tersebut. Di dalam Al-Qur'an telah banyak diterangkan mengenai hal berbakti terhadap orang tua, seperti yang telah dijelaskan sebelumnya. Walaupun tidak diperintah untuk mengasihi anak, otomatis orang tua mengasihi anaknya. Seorang ayah, apalagi seorang ibu, amat sayang kepada anaknya. Mereka sanggup bekerja bersusah payah siang dan malam membanting tulang, mencurahkan tenaga dan fikirannya. Semua itu demi kemaslahatan dan masa depan anaknya. Islam sangat menjunjung tinggi perbuatan bakti kepada orang tua. Akan tetapi, berbakti kepada orang tua ada batasnya, yakni selama perbuatan bakti tersebut tidak melanggar ketentuan yang telah di gariskan Allah Swt, baik yang telah dijelaskan dalam Al-Qur'an dan Hadist. Misalnya, jika orang tua memaksa anak untuk berbuat syirik atau melakukan kejahatan maka perintah orang tua tersebut wajib ditentang, namun ingat, harus dengan cara yang baik agar mereka tidak tersinggung.

Birrul walidain atau berbakti kepada kedua orang tua mempunyai kedudukan yang istimewa dalam ajaran Islam. Perkara berbakti kepada orang tua telah di atur baik dalam Al-Quran maupun Hadis. Perintah berbuat baik kepada ibu bapak diletakkan oleh Allah Swt di dalam AlQur'an langsung setelah perintah beribadah hanya kepada-Nya, sematamata atau sesudah larangan mempersekutukan-Nya. Allah Swt berfirman dalam surah al-Baqarah ayat 83 yang artinya: "Dan ingatlah ketika kami mengambil janji dari Bani Israil yaitu: Janganlah kamu menyembah selain Allah Swt., dan berbuat baiklah kepada ibu bapak..." (Qs. Al-Baqarah: 83).

Sedangkan dalam Hadis, Rasulullah Saw meletakkan birrul walidain sebagai amalan kedua terbaik sesudah salat tepat pada waktunya dan lebih diutamakan dari pada jihad dan hijrah. Sudah seharusnya kedua orang tua mendapatkan perlakuan yang baik dari anaknya sebagaimana mereka memperlakukan anaknya dari kecil hingga dewasa dengan baik. Islam memandang bagian ini lebih utama (didahulukan dari pada jihad dan hijrah). Namun banyak yang belum memahami apa yang diperintahkan oleh Al-Quran dan Hadis, untuk berbuat baik kepada kedua orang tua (Ahya, Muhammad, 2018).

\section{Hadis Tentang Perintah Birrul Walidain}

a. Shahih Bukhari No. 5515

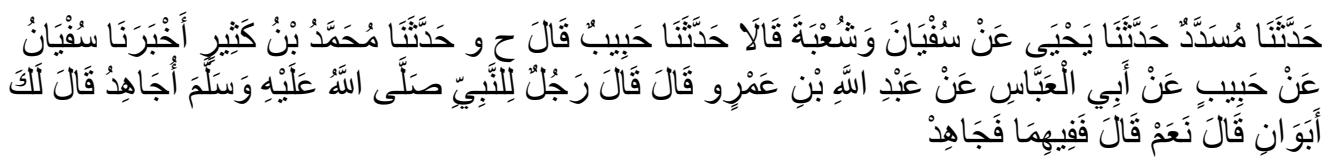


Telah menceritakan kepada kami Musaddad telah menceritakan kepada kami Yahya dari Sufyan dan Syu'bah keduanya berkata; telah menceritakan kepada kami Habib dia berkata. Dan diriwayatkan dari jalur lain, telah menceritakan kepada kami Muhammad bin Katsir telah mengabarkan kepada kami Sufyan dari Habib dari Abu Al 'Abbas dari Abdullah bin 'Amru dia berkata; seorang laki-laki berkata kepada Nabi shallallahu 'alaihi wasallam; "Saya hendak ikut berjihad." Beliau lalu bersabda: "Apakah kamu masih memiliki kedua orang tua?" dia menjawab; "Ya, masih." Beliau bersabda: "Kepada keduanya lah kamu berjihad."

Tabel 1. Daftar Rawi Sanad Riwayat Bukhari

\begin{tabular}{|c|c|c|c|c|c|c|c|}
\hline \multirow[t]{2}{*}{ No } & \multirow[t]{2}{*}{ Rawi Sanad } & \multicolumn{2}{|c|}{ Lahir/Wafat } & \multirow[t]{2}{*}{ Negeri } & \multirow[t]{2}{*}{ Kuniyah } & $\begin{array}{l}\text { Komentar } \\
\text { Ulama }\end{array}$ & \multirow[t]{2}{*}{ Kalangan } \\
\hline & & $\mathbf{L}$ & $\mathbf{W}$ & & & + & \\
\hline 1 & $\begin{array}{l}\text { Abdullah } \\
\text { bin 'Amru } \\
\text { bin Al 'Ash } \\
\text { bin Wa'il }\end{array}$ & & $63 \mathrm{H}$ & Maru & $\begin{array}{l}\text { Abu } \\
\text { Muhammad }\end{array}$ & Tsiqoh & Sahabat \\
\hline 2 & $\begin{array}{l}\text { As Saa'ib } \\
\text { bin Farruuk }\end{array}$ & & & $\begin{array}{l}\text { Marur } \\
\text { Rawdz }\end{array}$ & $\begin{array}{l}\text { Abu Al- } \\
\text { Abbas }\end{array}$ & Tsiqoh & $\begin{array}{l}\text { Tabi'in } \\
\text { kalangan } \\
\text { Pertengahan }\end{array}$ \\
\hline 3 & $\begin{array}{l}\text { Habib bin } \\
\text { abi Tsabit } \\
\text { Qais }\end{array}$ & & $\begin{array}{l}119 \\
\mathrm{H}\end{array}$ & Kufah & Abu Yahya & Tsiqoh & $\begin{array}{l}\text { Tabi'in } \\
\text { kalangan } \\
\text { pertengahan }\end{array}$ \\
\hline 4 & $\begin{array}{l}\text { Sufyan bin } \\
\text { Sa'id bin } \\
\text { Masruq }\end{array}$ & & $\begin{array}{l}161 \\
\mathrm{H}\end{array}$ & Kufah & $\begin{array}{l}\text { Abu } \\
\text { Abdullah }\end{array}$ & Tsiqoh & $\begin{array}{l}\text { Tabi'ut } \\
\text { Tabi'in } \\
\text { kalangan } \\
\text { tua }\end{array}$ \\
\hline 5 & $\begin{array}{l}\text { Muhammad } \\
\text { bin Katsir }\end{array}$ & & $\begin{array}{l}223 \\
\mathrm{H}\end{array}$ & Bashrah & $\begin{array}{l}\text { Abu } \\
\text { Abdullah }\end{array}$ & Tsiqoh & $\begin{array}{l}\text { Tabi'ut } \\
\text { Tabiin } \\
\text { kalangan } \\
\text { tua }\end{array}$ \\
\hline 6 & $\begin{array}{l}\text { Syu'bah bin } \\
\text { al-Hajjaj bin } \\
\text { Al Warad }\end{array}$ & & $\begin{array}{l}160 \\
\mathrm{H}\end{array}$ & Bashrah & $\begin{array}{l}\text { Abu } \\
\text { Bistham }\end{array}$ & Tsiqoh & $\begin{array}{l}\text { Tabi'ut } \\
\text { Tabuun } \\
\text { kalangan } \\
\text { tua }\end{array}$ \\
\hline 7 & $\begin{array}{l}\text { Yahya bin } \\
\text { Sa'id bin } \\
\text { Faruqh }\end{array}$ & & $\begin{array}{l}198 \\
\mathrm{H}\end{array}$ & Bashrah & Abu Sa'id & Tsiqoh & $\begin{array}{l}\text { Tabi'ut } \\
\text { Tabiin } \\
\text { kalangan } \\
\text { biasa }\end{array}$ \\
\hline 8 & $\begin{array}{l}\text { Musaddad } \\
\text { bin } \\
\text { Musrihad }\end{array}$ & & $\begin{array}{l}228 \\
\mathrm{H}\end{array}$ & Bashrah & $\begin{array}{l}\text { Abu Al- } \\
\text { Hasan }\end{array}$ & Tsiqoh & $\begin{array}{l}\text { Tabiin } \\
\text { kalangan } \\
\text { biasa }\end{array}$ \\
\hline
\end{tabular}

Tabel 1. adalah daftar rawi dan sanad dari hadis yang sedang diteliti. Pemasangan periwayat dilakukan secara urut, dari periwayat pertama 
hingga akhir. Hal ini dilakukan agar lebih memudahkan pembaca melihat posisi setiap periwayat. Periwayat hadis disebut rawi, sedangkan sanad adalah mata rantai periwayat hadis. Salah satu yang menentukan sebuah hadis dikatakan sahih adalah bila telah terverifikasinya seorang perawi hadis dengan baik, mengikuti standar yang telah ditetapkan olehkritikus hadis (Muzayyin, 2017). Hadis dinyatakan valid bila periwayat bernilai positif menurut komentar ulama serta transmisi bersambung menurut tahun kelahiran periwayat. Apabila teks hadis dimengerti menurut akal sehat serta tidak bertentangan dengan Al-Qur'an, maka hadis dikategorikan sebagai amal kebaikan yang menurut ulama tidak membutuhkan pengujian validitas (Mohammad Fajar Septian, Wahyudin Darmalaksana, Mulyana, 2021). Syarat hadis sahih juga sanad harus bersambung. Jika sanad hadis terputus, maka hadis tersebut termasuk hadis dhaif. Bukti sanad bersambung adalah bertemu antara guru dan murid (Muzayyin, 2017).

Syarah hadis telah dilakukan para ulama sejak zaman klasik dengan berbagai pendekatan (Mohammad Fajar Septian, Wahyudin Darmalaksana, Mulyana, 2021). Hadis tersebut menunjukkan bahwa jihad di jalan Allah yang sangat penting di awal masa Islam tidak diwajibkan bagi sahabat yang masih hidup orang tuanya. Jihad hanya diizinkan bagi mereka yang diizinkan oleh kedua orang tuanya. Bahkan Rasulullah memerintahkan agar sahabat berjihad kepada orang tuanya. Al-Asqalani mengatakan bahwa jihad kepada orang tua adalah jihad atau bersungguhsungguh dalam berbuat baik (birr) dan memberi kebaikan (ihsan) kepada kedua orang tua. Jihad tersebut posisinya sama dengan jihad memerangi musuh. Begitu juga dengan jihad agar tidak menyakiti keduanya. Al-Jauzi juga mengatakan bahwa hal terbaik secara hierarkis adalah berbuat baik dan bersedekah kepada ibu, ayah, kemudian diri sendiri, keluarga, kerabat dan terakhir adalah di jalan Allah. Berbuat baik kepada kedua orang tua tidak hanya waktu mereka hidup. Bahkan setelah meninggal, seorang anak dapat berbuat baik kepada kedua orang tuanya seperti memohonkan ampunan kepada mereka dan membacakan ayat Al-Qur'an untuk mereka. Menurut Al-Jauzi, hal tersebut pahalanya sama dengan haji mabrur. Al-Marwazi menambahkan bahwa menyambung silaturrahim kepada orang yang dulu sering disilaturrahimi oleh kedua orang tuanya juga merupakan (I'anah, Nur, 2017).

b. Shahih Bukhari No. 496

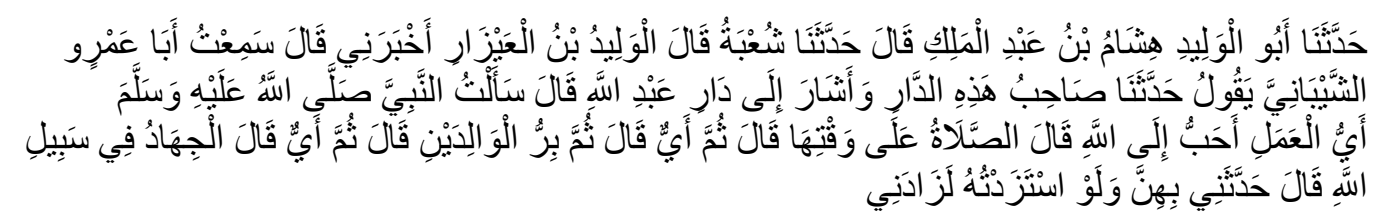


Telah menceritakan kepada kami Abu Al-Walid Hisyam bin 'Abdul Malik berkata, telah menceritakan kepada kami Syu'bah berkata, telah mengabarkan kepadaku Al-Walid bin Al-Aizar berkata, Aku mendengar Abu 'Amru Asy Syaibani berkata, "Pemilik rumah ini menceritakan kepada kami seraya menunjuk rumah 'Abdullah ia berkata," Aku pernah bertanya kepada Nabi shallallahu 'alaihi wasallam, "Amal apakah yang paling dicintai oleh Allah?" Beliau menjawab: "Shalat pada waktunya." 'Abdullah bertanya lagi, "Kemudian apa lagi?" Beliau menjawab: "Kemudian berbakti kepada kedua orangtua." Abdullah bertanya lagi, "Kemudian apa lagi?" Beliau menjawab: "Jihad fi sabilillah." Abdullah berkata, "Beliau sampaikan semua itu, sekiranya aku minta tambah, niscaya beliau akan menambahkannya untukku."

Tabel 2. Daftar Rawi Sanad Riwayat Bukhari

\begin{tabular}{|c|c|c|c|c|c|c|c|c|}
\hline \multirow[t]{2}{*}{ No. } & \multirow[t]{2}{*}{ Rawi Sanad } & \multicolumn{2}{|c|}{$\begin{array}{c}\text { Lahir/Wafa } \\
t\end{array}$} & \multirow[t]{2}{*}{ Negeri } & \multirow[t]{2}{*}{ Kuniyah } & \multicolumn{2}{|c|}{$\begin{array}{c}\text { Komentar } \\
\text { Ulama }\end{array}$} & \multirow[t]{2}{*}{ Kalangan } \\
\hline & & $\mathbf{L}$ & $\mathbf{W}$ & & & - & + & \\
\hline 1 & $\begin{array}{l}\text { Abdullah bin } \\
\text { Mas'ud bin } \\
\text { Ghafil bin } \\
\text { Habib }\end{array}$ & & $32 \mathrm{H}$ & Kufah & $\begin{array}{l}\text { Abu } \\
\text { 'Abdur } \\
\text { Rahman }\end{array}$ & & Tsiqoh & Sahabat \\
\hline 2 & Sa'ad bin Iyas & & $96 \mathrm{H}$ & Kufah & Abu Amr & & Tsiqoh & $\begin{array}{l}\text { Tabi'in } \\
\text { kalangan } \\
\text { tua }\end{array}$ \\
\hline 3 & $\begin{array}{l}\text { Al Walid bin } \\
\text { Al 'Ayzar bin } \\
\text { Huraits }\end{array}$ & & & Kufah & & & Tsiqoh & $\begin{array}{l}\text { Tabi'in } \\
\text { kalangan } \\
\text { biasa }\end{array}$ \\
\hline 4 & $\begin{array}{l}\text { Malik bin } \\
\text { Mighwal bin } \\
\text { 'Ashim }\end{array}$ & & $159 \mathrm{H}$ & Kufah & $\begin{array}{l}\text { Abu } \\
\text { Abdullah }\end{array}$ & & Tsiqoh & $\begin{array}{l}\text { Tabi'ut } \\
\text { Tabi'in } \\
\text { kalangan } \\
\text { tua }\end{array}$ \\
\hline 5 & $\begin{array}{l}\text { Muhammad } \\
\text { bin Sabiq, }\end{array}$ & & $213 \mathrm{H}$ & $\begin{array}{l}\text { Baghda } \\
\text { d }\end{array}$ & Abu Ja'far & & Tsiqoh & $\begin{array}{l}\text { Tabi'in } \\
\text { (tdk } \\
\text { jumpa } \\
\text { Shahabat) }\end{array}$ \\
\hline 6 & $\begin{array}{l}\text { Al Hasan bin } \\
\text { Ash Shabbah }\end{array}$ & & $249 \mathrm{H}$ & $\begin{array}{l}\text { Baghda } \\
\text { d }\end{array}$ & $\begin{array}{l}\text { Abu } \\
\text { Bistham }\end{array}$ & & Tsiqoh & $\begin{array}{l}\text { Tabi'ul } \\
\text { Atba' } \\
\text { kalangan } \\
\text { tua }\end{array}$ \\
\hline
\end{tabular}

Tabel 2. adalah daftar rawi dan sanad dari hadis yang sedang diteliti. Pemasangan periwayat dilakukan secara urut, dari periwayat pertama hingga akhir. Hal ini dilakukan agar lebih memudahkan pembaca melihat posisi setiap periwayat. Periwayat hadis disebut rawi, sedangkan sanad adalah mata rantai periwayat hadis. Salah satu yang menentukan sebuah 
hadis dikatakan sahih adalah bila telah terverifikasinya seorang perawi hadis dengan baik, mengikuti standar yang telah ditetapkan olehkritikus hadis (Muzayyin, 2017). Hadis dinyatakan valid bila periwayat bernilai positifmenurut komentar ulama serta transmisi bersambung menurut tahun kelahiran periwayat. Apabila teks hadis dimengerti menurut akal sehat serta tidak bertentangan dengan al-Qur'an, maka hadis dikategorikan sebagai amal kebaikan yang menurut ulama tidak membutuhkan pengujian validitas (Mohammad Fajar Septian, Wahyudin Darmalaksana, Mulyana, 2021). Syarat hadis sahih juga sanad harus bersambung. Jika sanad hadis terputus, maka hadis tersebut termasuk hadis dhaif. Bukti sanad bersambung adalah bertemu antara guru dan murid (Muzayyin, 2017).

Syarah hadis telah dilakukan para ulama sejak zaman klasik dengan berbagai pendekatan (Mohammad Fajar Septian, Wahyudin Darmalaksana, Mulyana, 2021). Salat didahulukan daripada berbakti kepada kedua orang tua, dan berbakti kepada kedua orang tua didahulukan daripada jihad di jalan Allah karena salat adalah hak Allah Swt yang merupakan kewajiban setiap umat Islam selama hidupnya, sedangkan berbakti kepada kedua orang tua itu kewajiban setiap orang selama kedua orang tuanya masih hidup dan ada beberapa hal yang juga harus dilakukan setelah mereka meninggal. Sementara jihad di jalan Allah apabila diartikan dengan perang, bukan kewajiban seperti kewajiban salat dan berbakti kepada kedua orang tua (Ahya, Muhammad, 2018).

\section{Bentuk-bentuk dan Keutamaan Birrul Walidain}

Berbakti kepada orangtua dapat ditunjukkan dengan cara tidak menyakiti hatinya serta senantiasa mematuhi perintahnya. Namun, ada juga cara lain yang bisa menunjukkan sikap birrul walidain seorang anak kepada orangtua. Adapun bentuk-bentuk birrul walidain, sebagai berikut:

Pertama, memuliakan orang tua. Salah satu karakteristik utama dari seorang muslim sejati adalah perlakukanlah dengan bijak dan baik kepada orang tuanya, sebabmemperlakuakn orang tua dengan hormat dan baik merupakan salah satu ajaran Islam. Rasulullah saw bersabda : "Sesungguhnya dosa yang paling besar di sisi Allah adalah dosa seseorang yang melaknat kedua orang tuanya "para sahabat bertanya, "bagaimanakan bentuknya seseorang itu melaknat kedua orang tuanya? "Rasullullah menjawab, seseorang mengeluarkan kata-kata yang isinya mencela dan menghina keduanya" (HR. Bukhari dari Abdullah bin Amr).

Kedua, mengikuti keinginan, dan mentaati saran orang tua dalam berbagai aspek kehidupan, baik masalah pendidikan, pekerjaan, jodoh, maupun masalah lainnya. Tentu dengan catatan penting selama keinginan dan saran-saran itu sesuai dengan ajaran Islam. Apabila bertentangan atau tidak sejalan dengan ajaran Islam, maka tidaklah punya kewajiban untuk 
Jurnal Riset Agama, Volume 1, Nomor 1 (April 2021): 45-58

Hofifah Astuti / Berbakti Kepada Orang Tua dalam Ungkapan Hadis

mematuhinya. Bahkan harus menolaknya dengan cara yang baik, seraya berusaha meluruskan.

Ketiga, menghormati kedua orang tua, dengan penuh rasa terima kasih dan kasih sayang atas jasa-jasa keduanya yang tidak mungkin bisa dinilai dengan apapun. Ibu yang mengandung dengan susah payah dan penuh penderitaan. Bapak yang membanting tulang mencari nafkah untuk ibu dan anak-anaknya. Banyak cara untuk menunjukkan rasa hormat kepada orang tua, antara lain memanggilnya dengan panggilan yang menunjukkan hormat, berbicara kepadanya dengan lemah-lembut, tidak mengungkapkan kata-kata kasar (apalagi kalau mereka berdua sudah lanjut usia), pamit kalau meninggalkan rumah (kalau tinggal serumah), memberi khabar tentang keadaan kita dan menanyakan keadaan keduanya lewat surat atau telepon.

Keempat, membantu ibu dan bapak secara fisik dan material. Misalnya sebelum berkeluarga dan mampu berdiri sendiri anak-anak membantu orang tua (terutama ibu) mengerjakan pekerjaan rumah, dan setelah berkeluarga atau berdiri sendiri membantu orang tua secara finansial, baik untuk membeli pakaian, makanan, minuman, dan lain-lain.

Kelima, selalu mendoakan ibu bapak semoga Allah Swt memberi ampunan, rahmat hidayat dan sebagainya.

Keenam, setelah orang tua meninggal dunia, birrul walidaian, masih bisa diteruskan dengan cara antara lain: meminta ampun kepada Allah Swt dengan taubat nashuha (jujur) bila kita pernah berbuat durhaka kepada keduanya di waktumereka masih hidup, menshalatkannya dan mengantarkan jenazahnya ke liang lahat, selalu memintakan ampunan untuk keduanya, membayarkan hutang-hutangnya, melaksanakan wasiat sesuai dengan syari'at, menyambung tali silaturahmi kepada orang yang keduanya juga pernah menyambungnya, memuliakan sahabatsahabatnya, dan selalu mendo'akan keduanya (Utami, 2017).

Sehubungan dengan keutamaan berbakti kepada kedua orang tua yang lebih utama dibandingkan dengan perbuatan baik lainnya bahkan termasuk dengan jihad (perang membela agama Allah Swt), berkaitan dengan hadits yang sudah di paparkan pada materi sebelumnya, bahwa Rasulullah adalah orang yang paling mengetahui baik buruknya (manfaat atau madharat) terhadap amal yang akan dilakukan oleh sahabatnya secara khusus dan oleh umatnya secara umum. Padahal pada saat itu Rasulullah memerlukan teman dan tenaga yang lebih banyak dalam melaksanakan hijrah dan jihadnya, akan tetapi bahwa lelaki yang datang kepadanya merupakan seseorang yang sangat dibutuhkan keberadaannya oleh kedua orang tuanya, akan lebih baik dan lebih manfaat apabila ia menemani kedua orang tuanya, dibandingkan mengikuti Rasulullah berhijrah dan berperang, dengan harapan kedua orang tuanya merasa senang dan gembira, atas keberadaan anaknya sehingga menjadi jalan 
Jurnal Riset Agama, Volume 1, Nomor 1 (April 2021): 45-58

Hofifah Astuti / Berbakti Kepada Orang Tua dalam Ungkapan Hadis

juga bagi lelaki itu untuk mendapatkan pahala dan ridho-Nya sebagaimana yang diharapkan sahabat Nabi tersebut.

Setelah menelaah dan memahami beberapa ayat dan hadits tentang berbakti kepada kedua orang tua ternyata perbuatan baik seseorang terhadap kedua orang tua itu telah Allah Swt dan Rasulullah himbau dan perintahkan agar manusia melaksanakan ihsannya (berbakti kepada kedua orang tua ibu bapaknya), karna Allah dan Rasulullah sangat mencintai amal tersebut (Rochman, 2010). Adapun keutamaan berbakti kepada kedua orang tua, di antaranya:

Pertama, berbakti kepada orang tua adalah amal yang paling utama. Dengan demikian jika ingin kebaikan harus didahulukan amal-amal yang paling utama di antaranya birrul walidain (berbakti kepada kedua orang tua).

Kedua, ridha Allah SWT tergantung kepada keridhaan orang tua dan murka Allah tergantung kepada murkanya rang tua. Hal ini sangatlah penting, dan perlu dicermati, bahwasannya restu atau ridho kepada orang tua merupakan wujud penghormatan kepada mereka. Maka dari itu kita harus senantiasa berusaha tidak membuat orang tua murka atau marah, karena marahnya orang tua sama dengan marahnya Allah kepada kita. Sebagaimana sabda Nabi Saw, yang terdapat dalam Kitab Bulughul Maram Hadis No. 1486, sebagai berikut:

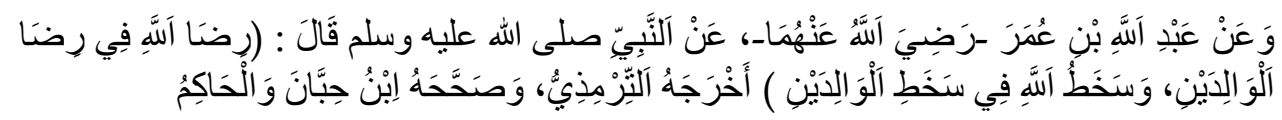

Dari Abdullah Ibnu Amar al-'Ash Radliyallaahu 'anhu bahwa Nabi shallallaahu 'alaihi wa sallam bersabda: "Keridhoan Allah tergantung kepada keridhoan orang tua dan kemurkaan Allah tergantung kepada kemurkaan orang tua" (Hadis Riwayat Tirmidzi. Hadis shahih menurut Ibnu Hibban dan Hakim).

Ketiga, menghilangkan kesulitan yang sedang dialami, yaitu dengan cara bertawasul dengan amal kebaikan. Ini menunjukkan bahwa perbuatan berbakti kepada kedua orang tua yang pernah kita lakukan, dapat digunakan untuk bertawasul kepada Allah Swt ketika kita mengalami kesulitan, insyaallah kesulitan tersebut akan hilang. Berbagai kesulitan yang dialami seseorang saat ini di antaranya karena perbuatan durhaka kepada kedua orang tuanya. Kalau kita mengetahui, bagaimana beratnya orang tua kita telah bersusah payah untuk kita, maka perilaku anak yang mencoba untuk membalas budi baik kepada ibu bapak saat ini, atau yang akan datang, itu pun belum sebanding dengan jasa orang tua ketika mengurus dan merawat kita sewaktu masih kecil.

Orang tua kita telah mengurus kita mulai dari kandungan dengan beban yang dirasakannya sangat berat dan susah payah. Demikian juga 
Jurnal Riset Agama, Volume 1, Nomor 1 (April 2021): 45-58

Hofifah Astuti / Berbakti Kepada Orang Tua dalam Ungkapan Hadis

ketika melahirkan, ibu kita mempertaruhkan jiwanya antara hidup dan mati. Ketika kita lahir, ibulah yang menyusui kita kemudian membersihkan kotoran kita. Semuanya dilakukan oleh ibu kita, bukan oleh orang lain. Ibu kita selalu menemani ketika terjaga dan menangis baik di pagi, siang atau malam hari. Apabila kita sakit tidak ada yang bisa menangis kecuali ibu kita. Sementara bapak kita juga berusaha agar kita segera sembuh dengan membawa ke dokter atau yang lain. Sehingga kalau ditawarkan antara hidup dan mati, ibu kita akan memilih mati agar kita tetap hidup. Itulah jasa seorang ibu terhadap anaknya. Oleh karena itu Rasulullah sampai menyebutkan ibu 3 kali dalam sabdanya :

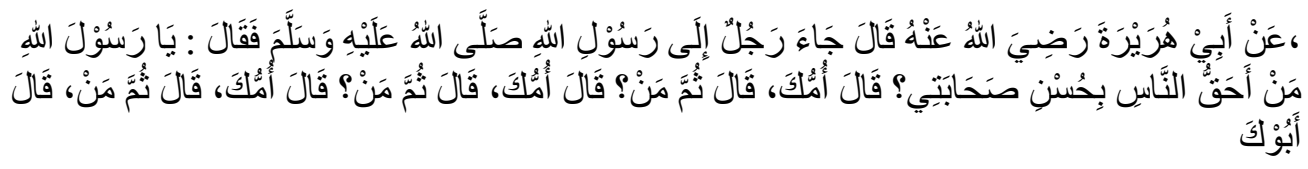

Dari Abu Hurairah radhiyallaahu 'anhu, beliau berkata, seseorang datang kepada Rasulullah shalallahu 'alaihi wa sallam dan berkata, "Wahai Rasulullah, kepada siapakah aku harus berbakti pertama kali?" Nabi shalallaahu 'alaihi wa sallam menjawab, "Ibumu!" Dan orang tersebut kembali bertanya, "Kemudian siapa lagi?" Nabi shalallaahu 'alaihi wa sallam menjawab, "Ibumu!" Orang tersebut bertanya kembali, "Kemudian siapa lagi?" Beliau menjawab, "Ibumu!" Orang tersebut bertanya kembali, "Kemudian siapa lagi," Nabi shalallahu 'alaihi wasallam menjawab, “Kemudian ayahmu” (HR. Bukhari No. 5971 dan Muslim No. 2548).

Keempat, diluaskan rizki dan dipanjangkan umur. Terdapat ayat-ayat Al-Qur'an atau hadis-hadis Nabi Saw yang menganjurkan untuk menyambung tali silaturahmi. Dalam silaturahmi yang harus didahulukan adalah kepada kedua orang tua sebelum kepada yang lain. Banyak diantara saudara-saudara kita yang sering ziarah kepada temantemannya tetapi kepada orang tuanya sendiri jarang bahkan tidak pernah. Padahal ketika masih kecil dia selalu bersama ibu dan bapaknya. Tapi setelah dewasa, seakan-akan dia tidak pernah berkumpul bahkan tidak kenal dengan kedua orang tuanya. Sesulit apapun harus tetap diusahakan untuk bersilaturrahmi kepada kedua orang tua. Karena dengan dekat kepada keduanya insyaallah akan dimudahkan rizki dan dipanjangkan umurnya. Sebagaimana dikatakan oleh Imam Nawawi bahwa dengan bersilaturrahmi akan diakhirkan ajal dan umur seseorang. Walaupun masih terdapat perbedaan dikalangan ulama tentang masalah ini, namun pendapat yang lebih kuat berdasarkan nash dan zhahir hadist ini bahwa umurnya memang benar-benar akan dipanjangkan.

Kelima, dimasukkan ke jannah (surga) oleh Allah Swt. Di dalam hadist Nabi Saw disebutkan bahwa anak yang durhaka tidak akan masuk surga. Maka kebalikan dari hadis tersebut yaitu anak yang berbuat baik 
Jurnal Riset Agama, Volume 1, Nomor 1 (April 2021): 45-58

Hofifah Astuti / Berbakti Kepada Orang Tua dalam Ungkapan Hadis

kepada kedua orang tua akan dimasukkan oleh Allah Swt ke jannah-Nya (surga). Dosa-dosa yang Allah Swt segerakan adzabnya di dunia di antaranya adalah berbuat dzhalim dan durhaka kepada kedua orang tua. Dengan demikian jika seorang anak berbuat baik kepada kedua orang tuanya, maka Allah Swt akan menghindarkannya dari berbagai malapetaka, dengan seizin Allah.

Tidak ada kebahagian yang orang tua rasakan selain melihat anakanaknya tumbuh menjadi orang yang berbakti dan berbudi luhur dalam kehidupan. tidak ada satu orang tua pun, yang berfikir jernih, menginginkan anak-anaknya terjerembab dalam jurang kenistaan dan kesengsaraan. Mereka akan berusaha sekuat tenaga menjadikan anakanakya sebagai orang yang sukses dan bahagian dalam kehidupanya baik di dunia maupun di akhirat. Maka dari itu marilah kita senantiasa berusaha untuk berlaku baik kepada keduanya.

\section{Simpulan}

Birrul walidain adalah berlaku baik kepada kedua orang tua, bersikap lemah lembut, tidak mengeraskan suara dihadapan kedua orang tua, tidak melawan, taat kepada keduanya, melaksanakan apa yang diridhai-nya, menjauhi apa yang membuat marah, menghormatinya, membahagiakannya, dan mendoakan keduanya baik ketika masih hidup ataupun sudah meninggal. Perintah berbakti kepada orangtua di dalam Al-Qur'an sejajar dengan perintah beriman dan beribadah kepada Allah. Menurut hadis, berbuat baik kepada orang tua merupakan jihad. Kualitas hadis ini sahih baik sanad maupun matan. Adapun keutamaan birrul walidain, di antaranya adalah berbakti kepada orang tua adalah amal yang paling utama, ridha Allah Swt tergantung kepada keridhaan orang tua, menghilangkan kesulitan yang sedang dialami, diluaskan rizki dan dipanjangkan umur, dan dimasukkan ke dalam jannah-Nya. Diharapkan penelitian ini memiliki implikasi manfaat bagi pengembangan khazanah pengetahuan Islam, terkhusus dalam praktiknya di masyarakat muslim. Bagaimana pun penelitian ini diakui memiliki keterbatasan dalam beberapa hal, yakni penggunaan jenis penelitian, penguasaan metode syarah hadis dan penerapan analisis. Sehingga dibutuhkan penelitian lanjutan, khususnya penelitian lapangan yang ditopang dengan metode yang tepat dengan pendekatan analisis yang lebih tajam.

\section{Daftar Pustaka}

Ahya, Muhammad. (2018). Birr Al-Walidain dalam Perspektif Hadis. UIN Syarif Hidayatullah Jakarta, 39-40. 
Jurnal Riset Agama, Volume 1, Nomor 1 (April 2021): 45-58

Hofifah Astuti / Berbakti Kepada Orang Tua dalam Ungkapan Hadis

Alihasan, M. R. (2018). Implemantasi Birrul Walidain Melalui Konikasi Verbal dan Non Verbal dalam Film "Ada Surga di Rumahmu". Universitas Islam Negeri Walisongo, 22.

Bahasa, T. P. (1989). Kamus Besar Bahasa Indonesia. Jakarta: Balai Pustaka.

Darmalaksana, W. (2020). Metode Penelitian Kualitatif Studi Pustaka Dan Studi Lapangan. Pre- Print Digital Library UIN Sunan Gunung Djati Bandung, - .

Elisa, Yuyun. (2018). Birrul Walidain dalam Perspektif Islam. Fakultas Tarbiyah dan Keguruan UIN Ar-Raniry Darussalam, 1-81.

Fathurrahman. (2007). Andai Kau Tahu Wahai Anakku. At-Tibyan, 26-27.

Hakim, Lukmanul. (2019). Studi Hadits Birrul Walidain. UIN Sunan ampel Surabaya, 1-64.

I'anah, Nur. (2017). Konsep Relasi Orang Tua dan Anak dalam Islam. Buletin Psikologi, 114-123.

Jamil, F. M. (2007). Andai Kau Tahu Wahai Anakku. Solo: At-Tibyan.

Mohammad Fajar Septian, Wahyudin Darmalaksana, Mulyana. (2021). Conference on Islamic and Socio Cultural Studies (CISS 2020). Gunung Djati Conference Series, 155-160.

Munawir, A. W. (1987). Kamus Besar Bahasa Arab Indonesia. Yogyakarta: Pustaka Pelajar.

Musfiroh, T. (2019). Makna Birrul Walidain Dalam Iklan Ramayana Edisi Ramadhan $1438 \mathrm{H}$ "Bahagianya adalah bahagiaku". UIN Walisongo Semarang, 28-29.

Muzayyin, A. (2017). Kualitas Hadis Ditentukan Oleh Kualitas Terendah Rawi Dalam Sanad. Al-Muta'aliyah STAI Darul Kamal NW Kembang kerang, 237-244.

Rochman, F. (2010). Berbakti kepada orang tua menurut penafsiran Hamka dalam tafsir al-Azhar dan Hasbi ash-Shiddieqy dalam tafsir an-Nur. IAIN Walisongo, 13-22.

Shaari, I. R. (2017). Konsep Pembinaan Birrul Walidain. Universitas Islam Negeri Ar-Rainiry Banda Aceh, 9.

Utami, K. W. (2017). Konsep Pendidikan Birrul Walidain dalam Al-Quran. Universitas Muhammadiyah Purwokerto, 22-69.

Zulhamdi. (2015). Konsep Birrul Walidain dalam Perspektif Hadis dam Relevansinya dengan Pembinaan Akhlak. IAIN Padangsidimpuan, 1116. 